\title{
Migraciones y COVID-19: Cuando el discurso securitista amenaza el derecho a la salud*
}

\author{
Migrations and COVID-19: when the securitist discourse \\ threatens the right to health
}

Migrações e COVID-19: quando o discurso securitista ameaça o direito à saúde

Recebido em 31-03-2021

Aceito para publicação em 20-05-2021

\section{doi) https://doi.org/10.47456/simbitica.v8i2.36378}

\section{Carolina Stefoni}

ORCID: 0000-0001-6949-2312

Socióloga Pontificia Universidad Católica de Chile, Magister en Estudios Culturales, Universidad de Birmingham y doctora en Sociología, Universidad Alberto Hurtado. Académica Universidad de Tarapacá-Chile. E-mail: cstefoni@gmail.com

\section{Báltica Cabieses}

ORCID: 0000-0003-0756-1954

Profesora titular, directora del Programa de Estudios Sociales en Salud, Instituto de Ciencias e Innovación en Medicina, Facultad de Medicina Clínica Alemana, Universidad del Desarrollo (Chile), PhD Ciencias de la Salud, epidemiología social de la Universidad de York (Reino Unido). E-mail: bcabieses@udd.cl

\section{Alice Blukacz}

ORCID: 0000-0001-6999-2421

Investigadora, Programa de Estudios Sociales en Salud, Instituto de Ciencias e Innovación en Medicina, Facultad de Medicina Clínica Alemana, Universidad del Desarrollo (Chile), MSc Migración Internacional y Políticas Públicas de la London School of Economics (Reino Unido). E-mal: a.blukacz@udd.cl

\section{Resumen}

El presente artículo analiza la coexistencia y relación entre dos enfoques que ha mantenido el Estado hacia la población migrante en Chile durante la actual pandemia por COVID-19. El primero está asociado a la perspectiva universalista de derechos humanos, que ha guiado los avances en el acceso a la salud de la población migrante. El segundo, en cambio, es de carácter excluyente y se desprende de una visión securitista con foco en el control de la migración irregular. En una primera lectura ambos enfoques pueden parecer opuestos, pero lo cierto es que se vienen aplicando simultáneamente, aunque

\footnotetext{
* Agradecemos a la Agencia Nacional de Investigación y Desarrollo (ANID) que financia el proyecto Fondecyt "Rutas y Trayectorias de migrantes venezolanos a lo largo de América del Sur" (N¹201130) y al Centro de Estudios de Conflicto y Cohesión Social (COES, ANID/FONDAP/15130009).
} 
con variaciones de intensidad de acuerdo a los distintos contextos políticos. A partir de trabajos previos realizados por las investigadoras analizaremos cómo ambos enfoques han impactado a la población venezolana en el país. Nos centraremos en el caso venezolano puesto que hoy día representa el $30 \%$ de la población extranjera y porque ha sido uno de los focos de las medidas implementadas por el gobierno en el último año.

Palabras claves: migración venezolana; pandemia; COVID19; derechos humanos; salud.

\section{Introducción}

La pandemia provocada por el Coronavirus SARS-CoV-2 es una de las peores crisis que ha debido enfrentar el mundo en las últimas décadas, producto tanto de su extensión global como del impacto que ha provocado en prácticamente todos los ámbitos de la vida. Y si bien todos hemos sido afectados de una u otra manera por la pandemia, lo cierto es que sus efectos se han distribuido acorde con las desigualdades estructurales presentes en cada una de las sociedades. El informe de la Comisión Económica para América Latina y el Caribe (CEPAL) (2020) indica que son las poblaciones más vulnerables las que están padeciendo de peor forma las consecuencias de la pandemia. En este contexto, la población migrante y refugiada ha sido definida como un sector que requiere atención prioritaria ya que una parte relevante se encuentra en condiciones de alta vulnerabilidad social. Dado lo anterior se ha llamado a implementar todas las medidas necesarias para proveer de protección y asistencia a personas que se encuentran en condiciones críticas, con especial foco en los desplazados, refugiados y personas en situación documental irregular (CEPAL, 2020). La protección que deben brindar los Estados requiere de un enfoque que comprenda la importancia de incluir a todas las personas, sin distinción de ningún tipo, en la política pública sanitaria. Sin embargo, esta aproximación va en una dirección distinta a la perspectiva de control y de seguridad que ha dominado la política migratoria en las últimas décadas.

En Chile la protección que ha brindado el Estado a la población migrante durante la pandemia se inscribe precisamente en esta tensión. Desde el ámbito de la salud se ha privilegiado un enfoque universalista entendiendo que el control de la pandemia requiere que toda la población sea parte de las medidas sanitarias (Cabieses et al., 2021b). Bajo este enfoque se ha provisto de medidas individuales y sociales de prevención, diagnóstico y tratamiento, incluyendo, por ejemplo, residencias sanitarias disponibles para todos los que la necesiten y el programa de vacunación nacional sin exclusión de ningún tipo, excepto turistas. También subsisten importantes barreras estructurales en el acceso a la salud de distintas 
comunidades en nuestro país, en especial de minorías sociales, las que dificultan su protección contra COVID-19 y la capacidad de amortiguar sus efectos sociales (Cabieses et al., 2021b). Estas barreras se vinculan, por una parte, a las brechas sistemáticas de acceso y uso efectivo de prestaciones sanitarias que posee el sistema de salud en Chile y que afecta al conjunto de la población. Por otra parte, refieren a condiciones que derivan de la propia situación migratoria como es la falta de documentos, discriminación en la atención por parte de funcionarios de la salud, temor de acercarse a un consultorio por estar en situación irregular, mayor concentración en empleos con condiciones laborales más precarias y más expuestas al contagio, y altos niveles de hacinamiento, entre otros (Bojorquez et al. 2021; Cabieses et al., 2021a).

Frente a la lógica universalista que ha primado en el área de la salud -y que busca dar atención sin exclusiones, pero que encuentra limitaciones producto de barreras estructurales, se contrapone la mirada de seguridad y control presente en una serie de medidas adoptadas durante 2020, las que mantienen una continuidad con aquellas adoptadas en años anteriores (Acosta; Freier, 2015; Freier; Vera, 2021; Stefoni; Brito, 2019; Vásquez; Finn; Umpierrez, 2021). Este enfoque estuvo presente en la discusión legislativa sobre la Ley de migración, ingresada en 2018 y aprobada por el legislativo a finales de 2020. El reciente discurso del Presidente Piñera el día que promulgó la ley (11 de abril de 2021), resume lo que ha sido este enfoque: “(la ley permite) poner orden en nuestra casa, a través de una política ordenada, segura y regular, permitir la migración legal y combatir la inmigración ilegal [...] No queremos que ingresen a nuestro país el crimen organizado, el contrabando, el narcotráfico y aquellos que no respetan nuestras leyes [...] quienes intenten ingresar clandestinamente, no solo cometen un delito, sino que se arriesgan a ser sujetos de expulsión” (La Tercera, 11 abril 2021).

Ambos enfoques están presentes en la relación que ha mantenido el Estado con la población migrante durante la pandemia, uno de carácter universalista que se desprende del ámbito sanitario, y otro de carácter excluyente que se desprende de la visión securitista y que tiene como foco el control de la migración irregular. Si bien en una primera lectura ambos enfoques pueden parecer opuestos, lo cierto es que en diversas ocasiones han logrado articularse, supeditando la visión universalista a la securitaria, como ocurrió en las medidas adoptadas a partir del incremento de cruces irregulares en Colchane, en el norte del país, en la frontera entre Chile y Bolivia. Allí se establecieron medidas mínimas para esta población y se reforzó la idea de expulsión una vez que hubiesen recibido estos mínimos cuidados. 
Nuestro artículo busca analizar estas perspectivas y comprender cómo ellas han impactado a la población venezolana en el país. Nos centraremos en el caso venezolano puesto que hoy día representa el $30 \%$ de la población extranjera en Chile y porque ha sido uno de los focos de las medidas implementadas por el Estado en el último año. Este artículo utiliza fuentes primarias provenientes de distintos estudios que han realizado las autoras en el contexto de la pandemia. Enumeramos a continuación estas investigaciones:

- Inserción socio-laboral de la población venezolana en Chile. Investigación coordinada por Stefoni en base a una metodología multi-métodos que incluyó una encuesta en línea a población venezolana en la Región Metropolitana (RM) y Región de Los Lagos (sur del país). Contestaron la encuesta 355 personas, de las cuales 36,5\% correspondió a hombres (133) y $62,5 \%$ a mujeres (222); 60,8\% de los encuestados residen en la Región de los Lagos y el 32,7\% (116) en la región Metropolitana. El estudio contempló además la realización de 20 entrevistas cualitativas a personas venezolanas hombres y mujeres residentes en Santiago y en la Región de Los Lagos. La investigación contó con financiamiento de la Fundación Konrad Adenauer (KAS).

- Proyecto del Fondo Nacional de Desarrollo Científico y Tecnológico (FONDECYT-Regular $\left.\mathrm{N}^{\circ} 1201130\right)$ "Rutas y trayectorias de migrantes venezolanos a lo largo de América del Sur. Cuando las puertas comienzan a cerrarse" (2020-2024). Este proyecto aporta con la investigación realizada sobre ingresos irregulares en el norte del país.

- Proyecto de Sistematización de la Respuesta Sanitaria de los Países Andinos ante la Migración Venezolana: El Caso de Chile. Investigación multi-país en la región andina y liderada en Chile por Cabieses, B., en base a metodología multi-métodos que incluyó (i) una revisión documentaria con búsqueda en literatura científica y gris (no convencional) nacional e internacional, (ii) un estudio cualitativo en base a 19 entrevistas semiestructuradas a personas migrantes de distintas nacionalidades, autoridades sanitarias, equipos de salud, expertos académicos, activistas sociales y organismos internacionales, (iii) estudio cuantitativo con análisis secundario de bases de datos del país, en particular la Encuesta de Caracterización Socioeconómica Nacional CASEN y la base de egresos hospitalarios del país. La investigación contó con financiamiento de United Kingdom Research and Innovation (UKRI). Los resultados del estudio están disponibles en Cabieses et al. (2021b).

- Migrantes Internacionales en Residencias Sanitarias en Chile durante la Pandemia COVID-19: Hacia una Respuesta Ética en Emergencias Sanitarias. Investigación liderada por Cabieses y Obach en base a un estudio multi-métodos en dos etapas, enfocado en la Región Metropolitana de Santiago y las regiones de Tarapacá, Arica y Parinacota y Antofagasta (en el norte chileno): (i) revisión de literatura científica sobre residencias sanitarias en migrantes, y (ii) estudio cualitativo que incluyó 30 entrevistas semi-estructuradas a diversos actores clave involucrados en residencias sanitarias en Chile. Entre estos actores se encontraban migrantes internacionales de distintas nacionalidades que habían estado en residencias, equipos de salud que trabajaban en residencias, managers de residencias, autoridades locales en los territorios y expertos nacionales (financiamiento OMS). Los resultados de esta investigación están disponibles en Cabieses et al. (2021c).

- Vulnerabilidades y recursos de comunidades migrantes internacionales en Chile para enfrentar la pandemia SARS-CoV-2: Construyendo estrategias diferenciadas desde la interculturalidad. Investigación liderada por Cabieses y Obach en base a un estudio multi-método enfocado en la Región Metropolitana y las regiones de Arica y Parinacota y Antofagasta: (i) encuesta en línea enfocada en personas migrantes internacionales $(n=990)$, y (ii) entrevistas semi-estructuradas 
$(\mathrm{n}=40)$ a personas migrantes internacionales y expertos del área social y de salud. La investigación contó con financiamiento de la Dirección de Investigación y Doctorados (DID) de la Universidad del Desarrollo (UDD) y fue incluido como estudio ANID COVID-19) código COVID0873 ${ }^{1}$. Los resultados de la investigación están disponibles en el estudio Cabieses et al. (2021d).

El artículo se divide en cinco secciones. La primera permite situar teóricamente la discusión entre lo que han sido las políticas universalistas y las políticas basadas en un sistema de control migratorio y de fronteras. La segunda entrega una breve caracterización de la población venezolana en Chile para comprender precisamente algunas de las barreras que mencionamos en el acceso a la salud. La tercera parte analiza las medidas que se han adoptado hacia la población migrante desde el ámbito de la salud y desde el ámbito de la política migratoria. Allí mostraremos que si bien ambas responden a enfoques distintos, en circunstancias específicas entran en tensión y puede supeditarse una a la otra. La cuarta sección analiza, en base a los resultados de las investigaciones señaladas, algunas consecuencias de la pandemia para las personas migrantes venezolanas que se encuentran en el país. En esta sección nos interesa mostrar los efectos que ambos enfoques tienen en la población migrante. Finalmente, la quinta sección entrega algunas reflexiones finales respecto de la ambivalencia en la forma cómo se ha abordado la migración venezolana en el país. Los resultados de esta reflexión podrían ser aplicados a otros colectivos nacionales, pero para ello habría que identificar algunos elementos vinculados con esos otros colectivos, antes de extrapolar los resultados.

\section{Conceptos de interés}

La consolidación del Estado-nación durante los siglos XIX y XX, así como el desarrollo del Estado de Bienestar Social en algunos países del Norte Global en la segunda mitad del siglo XX, contribuyó a fortalecer el concepto de ciudadanía enfatizando el reconocimiento de la condición de igualdad entre quienes eran considerados ciudadanos de un país. En virtud de ello, se reconoció también la responsabilidad por parte de los Estados en garantizar los derechos civiles, políticos y sociales de los ciudadanos (Kymlicka \& Wayne, 1994). Esta forma de comprender la ciudadanía asume que quienes viven en el territorio administrado por el Estado son nacionales y, en cuanto tales, son ciudadanos con derechos. Es decir, asume la existencia de una comunidad relativamente homogénea en términos culturales

\footnotetext{
${ }^{1}$ ANID-COVID-19 es un fondo especial de la Agencia Nacional de Investigación y Desarrollo (ANID) para el desarrollo de investigación asociado al COVID-19 y la pandemia.
} 
y un carácter universal en la promulgación de estos derechos. Sin embargo, estos dos supuestos quedaron en suspenso a partir del reconocimiento de las diversidades que constituyen a las sociedades y las movilidades constantes de personas en distintas direcciones (norte-sur, sur-sur, sur-norte y norte-norte). Así, el concepto de ciudadanía es tensionado en dos de sus supuestos centrales: la idea de homogeneidad al interior de la comunidad nacional y el carácter universal de los derechos puesto que sólo son reconocidos para quienes son considerados ciudadanos de un territorio, excluyendo a personas migrantes que no cuentan con el permiso de residencia.

Las sociedades actuales son testigo de la presencia creciente de personas que viven cotidiana y permanentemente en países distintos a los que nacieron. Estas personas trabajan, tienen familia, habitan las ciudades, y sin embargo no llegan a ser considerados miembros plenos del Estado particular en el que viven, por lo que no pueden gozar de los mismos derechos que este provee a sus ciudadanos. Por otra parte, se constata un evidente fracaso de la ideología asimilacionista que asumía el predominio de la cultura dominante frente a la diversidad cultural y social aportada por migrantes que llegaban como refugiados, trabajadores invitados o migrantes en busca de oportunidades laborales. El supuesto de que existe una nación homogénea en términos sociales y culturales, contenida bajo los límites territoriales y administrativos del Estado dio paso a una comprensión más compleja de la sociedad en la medida en que se reconoce la creciente diversidad que las constituye (Kymlicka, 2012). Ambos elementos, la coexistencia de ciudadanos y no-ciudadanos al interior del Estado-nación, y la realidad multicultural que experimentan las sociedades modernas llevaron a la necesidad de revisar la definición clásica de ciudadanía y sus supuestos de universalidad y homogeneidad cultural que se daban por hecho.

Es posible identificar al menos tres tipos de respuestas políticas frente a este cuestionamiento. En primer lugar, aquella que persevera en un proyecto asimilacionista en donde las y los migrantes deben adaptarse a la sociedad de llegada. Dicha adaptación supone la modificación de sus pautas culturales y sociales, bajo el supuesto de que esta adaptación conllevará su paulatina integración hasta ser considerados "uno más de la comunidad". En esta postura se establece un principio universal de derechos para aquellos que son miembros de la comunidad, pero define claramente un criterio excluyente para aquellos que no lo son, pese a residir en el mismo territorio. De ahí que las críticas a esta visión apuntan por una parte a la ausencia del derecho a la diferencia, y a la invisibilización de los factores y condiciones que generan la exclusión - y la consecuente discriminación- que subsisten bajo estas formas de reconocimiento parcial por parte del Estado. 
Un segundo tipo de respuesta enfatiza la racionalidad económica. Aquí la valoración de los migrantes se funda en el aporte que pueden hacer al desarrollo en las sociedades de destino. El problema con esta aproximación es que el fundamento que sostiene la legitimidad del reconocimiento y la inclusión se vuelve un péndulo que oscila entre el reconocimiento y la negación de este según cambien las condiciones del contexto, o la situación de los propios migrantes. Dicho de otro modo, los problemas comienzan cuando los migrantes pierden el empleo, dejan de ser una contribución a la economía local o cuando sobreviene una crisis económica más amplia. Cabe preguntarse aquí ¿qué ocurre cuando la ecuación instrumental se invierte y los migrantes dejan de ser percibidos como una contribución al desarrollo? Desde esta aproximación la población migrante pierde su legitimidad y con ello se puede llegar a cuestionar los derechos que hasta entonces les eran reconocidos precisamente en virtud de su contribución económica. La figura del migrante como un "chivo expiatorio" analizada por Wieviorka (2002) explica en parte el crecimiento de la xenofobia y racismo hacia la población migrante.

Un tercer tipo de respuesta busca incluir como ciudadanos a personas extranjeras residentes en dicho lugar. Autores como Baubock (2006), Soysal (1995) y Brubaker (2010), entre otros, señalan que la membresía, es decir el reconocimiento que otorgan los Estados a aquellos que pertenecen a dicha comunidad, es una condición simultánea de inclusión (definir quienes pertenecen) y exclusión (definir quienes no pertenecen). El criterio utilizado para definir la pertenencia ha sido históricamente el de nacionalidad, sea por ius solis, es decir quienes nacen en dicho territorio, o ius sanguinis, quienes heredan esta condición (Guizardi; Moraga; Garcés, 2014). Sin embargo, en el contexto migratorio actual, la presencia de migrantes residentes, así como inmigrantes indocumentados y refugiados, introduce un elemento de quiebre en el supuesto de que los ciudadanos corresponden sólo a los nacionales de un Estado nación. La ausencia de universalidad en el principio de igualdad se debe a la exclusión que experimentan aquellas personas que, viviendo y trabajando en un determinado país, no son reconocidos como ciudadanos en igualdad de condiciones que los locales. La necesidad de desvincular nacionalidad con ciudadanía, e incluir nuevos criterios que permitan otorgar membresía a aquellas personas que residen en un país, tal como el avecindamiento o el arraigo, han sido parte de las propuestas para avanzar en inclusión y reconocimiento, o en otras palabras, igualdad entre todos aquellos que viven en un mismo territorio y libertad para poder desarrollar y reproducir las distintas culturas de las cuales todos los ciudadanos son parte (Bauböck, 2006; Brubaker, 2010; De Lucas, 2009; Goldring; Landolt, 2013; Soysal, 1995). 
Siguiendo a de Lucas (2009) y Ferrajoli (2008) planteamos la importancia de reconocer el estatus de ciudadanos a los migrantes residentes. Ello permite garantizar los derechos de todas las personas que habitan un territorio bajo las mismas condiciones que los nativos, sin poner en cuestionamiento la soberanía del Estado. Sin embargo, esta mirada se tropieza constantemente con la lógica excluyente del Estado-nación, que utiliza el proceso de fronterización como una estrategia o herramienta para situar al migrante al otro lado de la distinción que divide a los nacionales de los extranjeros. La frontera condensa la tensión que enfrenta el derecho a migrar con la soberanía de los Estados para definir quién pertenece o no a la comunidad nacional, (De Lucas, 2003; Ghosh, 2008; Kearney, 2004). Autores como De Génova (2013) o Domenech (2009) plantean que esta tensión ha estado a la base de las políticas de control desde la configuración del Estado-nación (De Genova, 2013; Domenech, 2009).

Al pasar del estudio de la frontera al estudio sobre el proceso de fronterización (Zapata-Barrero, 2013), observamos cómo esta se transforma en la herramienta con que cuentan los Estados y los mercados para diferenciar y jerarquizar los movimientos de personas: turistas de potenciales trabajadores; businessman de posibles refugiados, trabajadores calificados de trabajadores para la agricultura y la construcción. La frontera nunca es un cierre absoluto, sino un ejercicio que transforma la movilidad de personas en política para decidir cómo y quiénes pueden efectivamente moverse (De Genova, 2015).

En el contexto de la pandemia, el enfoque de control y seguridad nacional buscó reducir la movilidad humana, argumentando el riesgo que ello podría significar para la expansión del virus (aunque el cierre fue mucho más enfático en los pasos fronterizos terrestres que en los aéreos). Por otra parte, las medidas sanitarias se anclaron en un principio universal, donde todas las personas residentes del país (con o sin documentos) deberían recibir la atención necesaria para controlar la expansión del virus. A continuación, revisaremos algunas características que presenta la población venezolana en términos de acceso a determinados servicios sociales y que resultan claves para comprender los posteriores efectos que tiene la pandemia sobre este colectivo.

\section{Breve caracterización de la población venezolana en Chile}

De acuerdo con las estimaciones realizadas por la Plataforma Regional de Coordinación Interagencial para Refugiados y Migrantes son cerca de 5,6 millones de personas refugiadas y migrantes las que han salido de Venezuela (R4V, 2020). Chile es el 
tercer país de recepción de esta población, con cerca de 457.300 personas, la mayoría de las cuales habría ingresado al territorio nacional con posterioridad a 2017 (OEA, 2020). El Instituto de Estadísticas de Chile (INE) y el Departamento de Extranjería y Migraciones (DEM) concluyeron una cifra muy similar de venezolanos/as en el país a diciembre de 2019 (455.494 personas), lo que equivale al 30,5\% del total de la población extranjera (INE DEM, 2020). La presencia ente hombres y mujeres es bastante similar (50,3 y 49,6\% respectivamente). En términos de distribución territorial, la población venezolana se concentra, al igual que la mayoría de los colectivos, en la Región Metropolitana de Santiago (RM). De acuerdo con CASEN 2017 el 87,3\% de este colectivo residía en la RM, mientras que sólo el 1,6\% lo haría en la macrozona norte, 10,1\% en la macrozona centro y el 1,1\% en la macrozona sur-austral ${ }^{2}$ (Cabieses et al., 2021b).

Una de las características de este colectivo es el alto nivel educacional que posee. El siguiente gráfico, en base a la información de la CASEN 2017, muestra no sólo que se trata de una población con un porcentaje muy alto de profesionales, sino que además casi triplica el porcentaje de personas con estudios de posgrado que presenta la población nacional.

Gráfico 1 - Nivel educacional

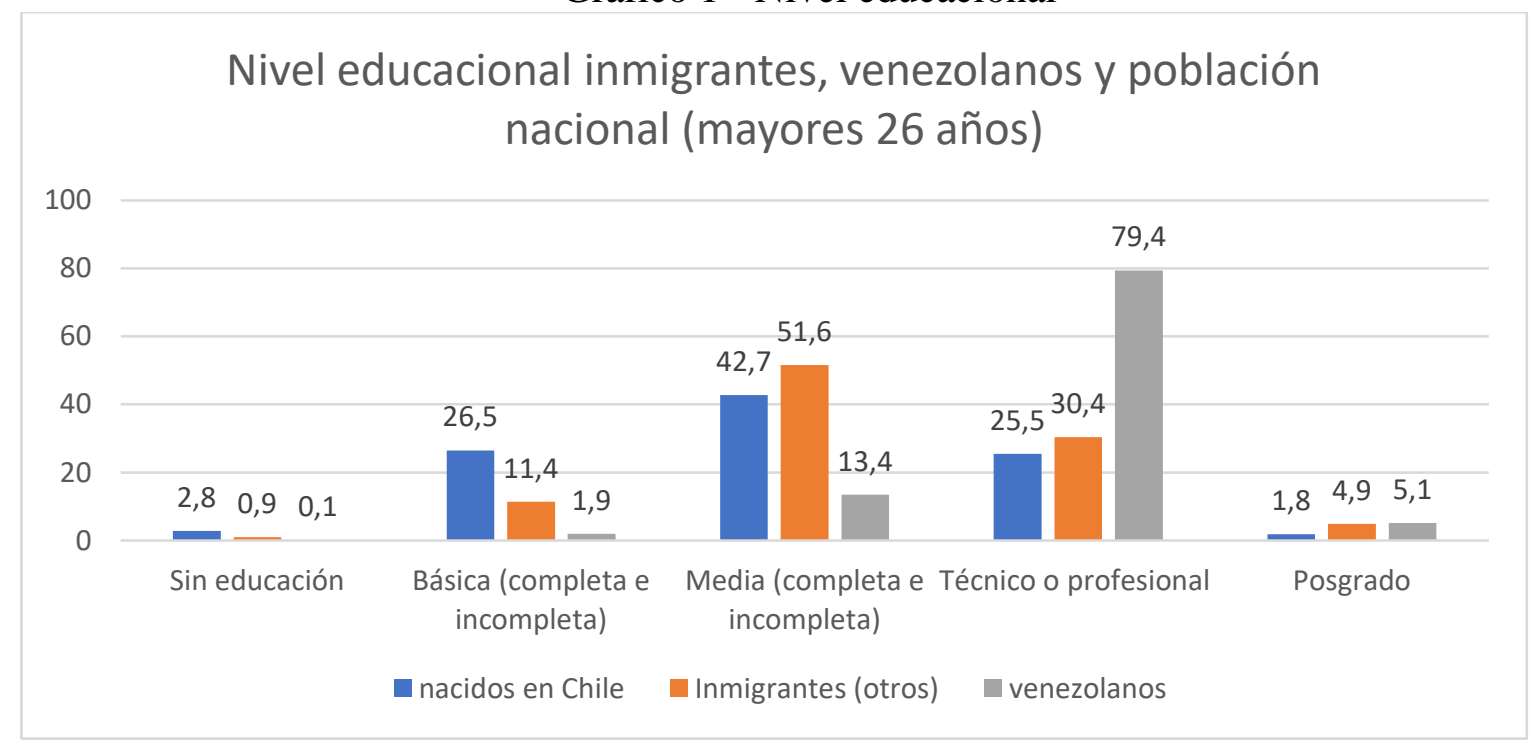

Fuente: Elaborado en base a estudio realizado por Cabieses et al. (2021b:19-33).

\footnotetext{
${ }^{2}$ La macrozona norte incluyó las regiones de Arica y Parinacota, Tarapacá, Antofagasta y Calama. La macrozona centro incluyó las regiones de Coquimbo, Valparaíso, O’Higgins, Maule. La macrozona Sur-Austral incluyó las regiones del Bíobío, Araucanía, Los Ríos, Los Lagos, Aysén y Magallanes. La RM dado su gran tamaño, se consideró separada del resto.
} 
Un segundo elemento importante de considerar es el acceso a la vivienda, el trabajo y la salud de esta población. Tanto la población inmigrante en general, como la población venezolana en particular, presentan mayores niveles de hacinamiento para las categorías medio bajo, medio alto y hacinamiento crítico. Sin embargo, la población venezolana presenta un porcentaje menor de personas viviendo en hacinamiento crítico, en comparación con el resto de la población migrante.

Gráfico 2 - Nivel hacinamiento (CASEN, 2017)

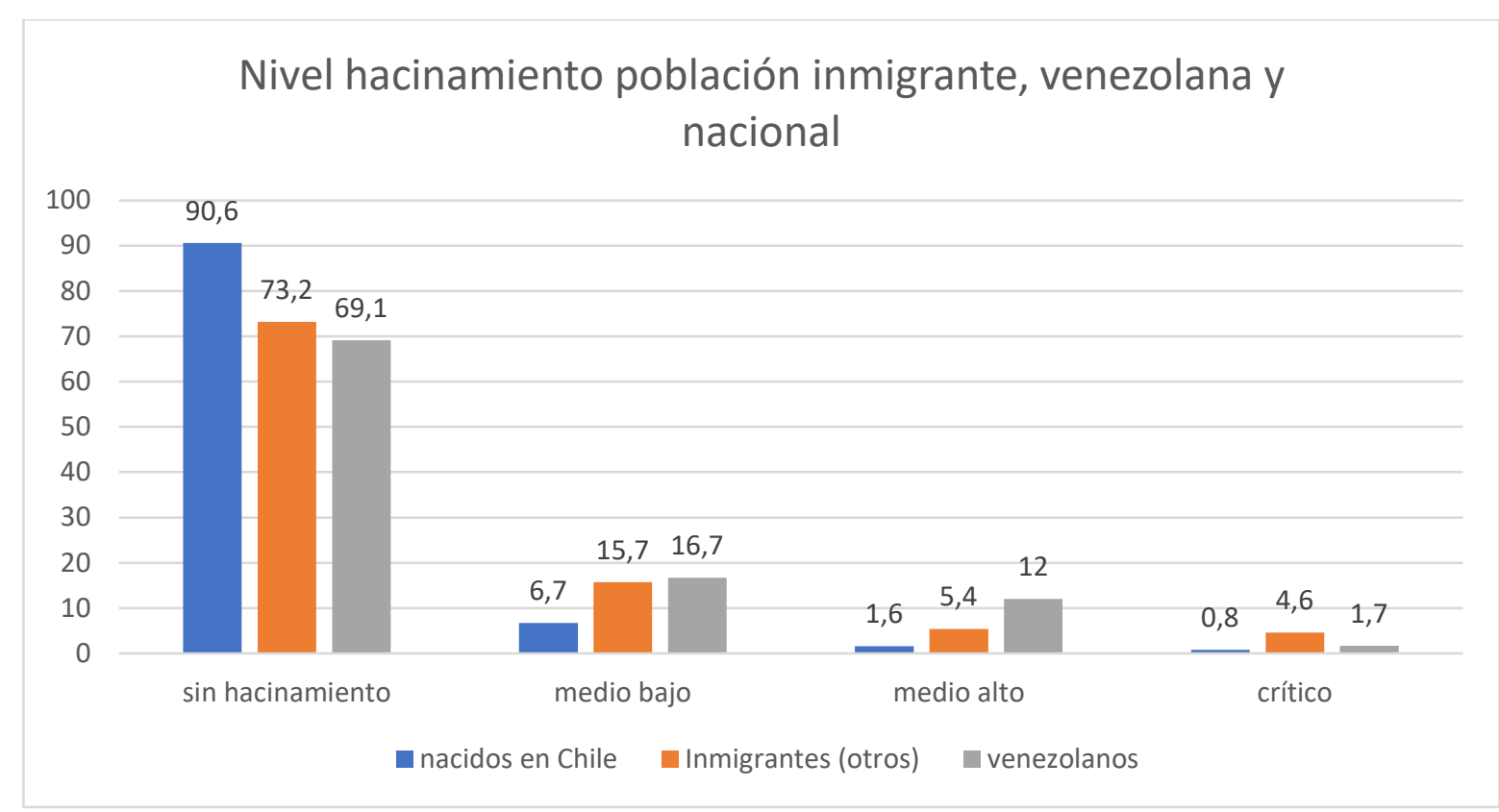

Fuente: Elaborado en base a estudio realizado por Cabieses et al. (2021b:19-33).

En cuanto al acceso al mercado del trabajo, la población inmigrante siempre ha mostrado una alta participación, muy por sobre la población local. Sin embargo en el caso venezolano esta participación es aún más alta que la población migrante, lo que da cuenta de la centralidad que tiene la búsqueda de empleo y condiciones de vida para este colectivo, tal como ha sido documentado en la literatura internacional (Cabieses et al., 2021b). 
Gráfico 3 - Ocupados, desocupados e inactivos.

Población nacional e inmigrante (CASEN 2017)

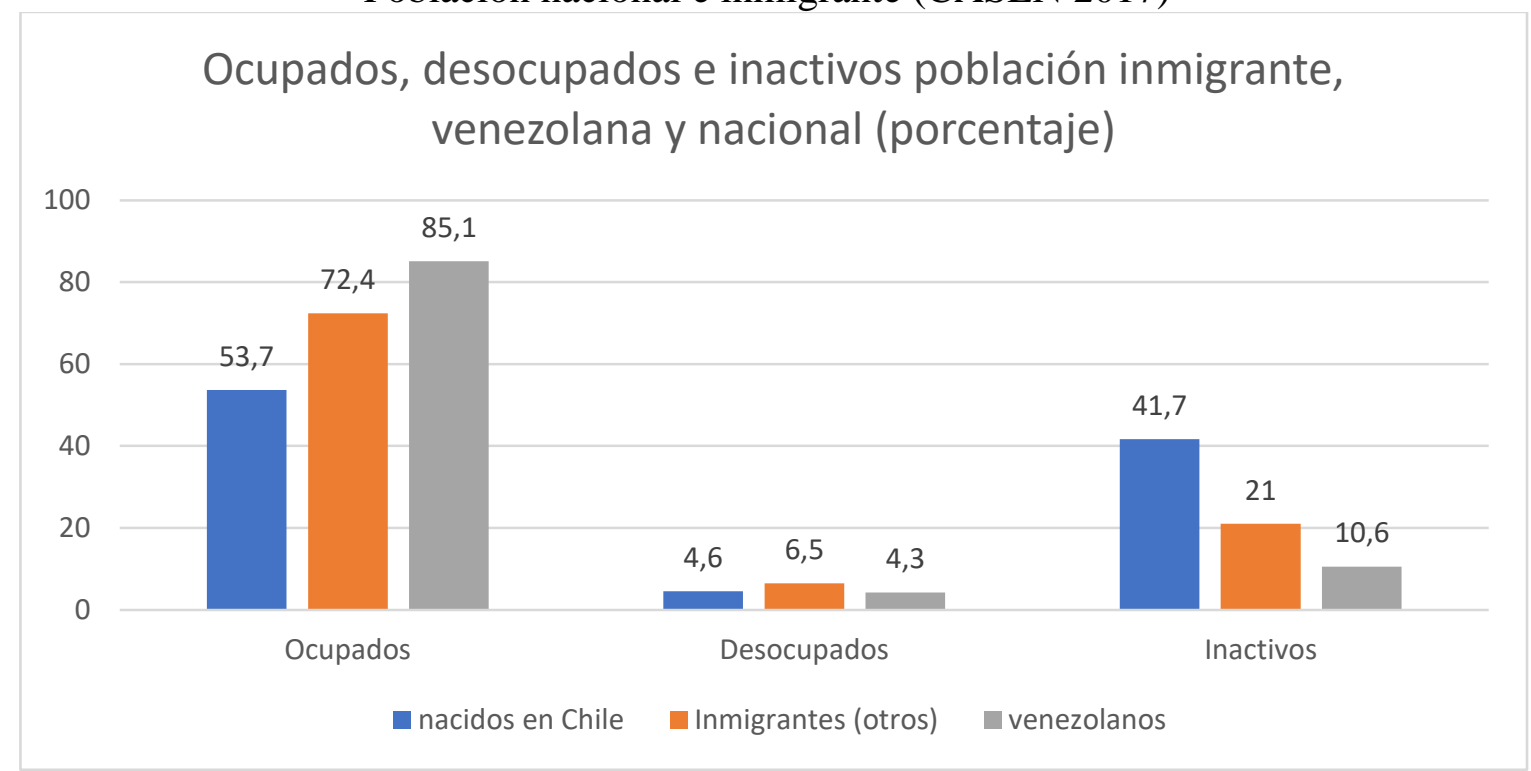

Fuente: Elaborado en base a estudio realizado por Cabieses et al. (2021:19-33).

En términos de acceso al sistema de salud, para comprender la situación de la población venezolana, es necesario indicar brevemente algunas de las características del sistema de salud en Chile. Se trata de un sistema segmentado y fragmentado con participación pública y privada. Es segmentado porque coexisten subsistemas con distintas modalidades de financiamiento y provisión, orientados hacia distintos segmentos de la población, definidos usualmente según ingresos, capacidad de pago posición social. Por otra parte el sistema es fragmentado debido a que la red de provisión de servicios -tanto a nivel privado como público- no se encuentra integrada. Por ejemplo, los centros de atención primaria y hospitales no están coordinados entre ellos. Esto se traduce en que es el paciente quien debe navegar entre la atención primaria y en hospitales, y no el sistema el que conduce al paciente. Algunas de las consecuencias de esta fragmentación es la duplicación de servicios, genera competencia entre los centros y hace ineficiente el uso de los recursos (Cabieses et al. 2021b).

Existe un sector público que cubre en torno al $75 \%$ de la población, especialmente a los más añosos, enfermos y pobres, y un sector privado que cubre a cerca del $20 \%$ de la población, generalmente jóvenes y personas con más recursos, quienes acceden a clínicas 
privadas. En tercer lugar existe el sistema de fuerzas armadas que cuentan con sus propios hospitales y centros de salud (Cabieses et al., 2021b)

El financiamiento en el sector público se encuentra centralizado en un único pagador, el Fondo Nacional de Salud (FONASA). Si bien categoriza a afiliados según su nivel de ingresos (categorías A, B, C y D), opera con un único fondo mancomunado que asegura transferencias entre sujetos con mayores y menores ingresos. Cabe destacar que la atención primaria depende en su mayoría de la administración municipal. En el sistema privado existen múltiples aseguradoras llamadas Instituciones de Salud Previsional (ISAPRES). En la práctica las ISAPRES recaudan por las cotizaciones obligatorias y por aportes voluntarios de las personas al afiliarse a alguno de los planes disponibles. Uno de los principales problemas estructurales del sistema actual es la ausencia de un modelo solidario que permita un mejor financiamiento del sistema público. Por otra parte el sistema privado incurre en una serie de prácticas que terminan por expulsar a quienes pierden la capacidad de pago, presentan enfermedades más complejas o envejecen (Cabieses et al., 2021b).

La Encuesta CASEN 2017 indica que el 22,1\% de la población venezolana no está adscrito a ningún sistema de salud, cifra muy superior al 13,8\% que presentan los inmigrantes, y al 2,2\% que presenta la población nacida en Chile. Por otra parte el $26 \%$ de la población venezolana residente reportó estar adscrita a los tramos del Fondo Nacional de Salud (FONASA) destinado a personas carentes de recursos o con menores ingresos (A y B), mientras que la inscripción al sistema privado es de 16\% (Tabla $N^{\circ} 1$ ). Cabe señalar que según un análisis basado en auto reporte de condición de salud, la población venezolana en Chile por lo general considera su salud como muy buena (Cabieses et al., 2021a)

Tabla 1 - Distribución de acceso al sistema de salud chileno de parte de migrantes internacionales de origen venezolano, de otras nacionalidades y población total. Encuesta CASEN 2017

\begin{tabular}{|l|l|l|l|l|}
\hline & \multicolumn{1}{|c|}{$\begin{array}{c}\text { Nacidos en } \\
\text { Chile }\end{array}$} & \multicolumn{1}{|c|}{$\begin{array}{c}\text { Inmigrantes } \\
\text { (otros) }\end{array}$} & \multicolumn{1}{|c|}{ Venezolanos } & \multicolumn{1}{|c|}{} \\
\hline Ninguna & $2,2 \%$ & $13,8 \%$ & $22,1 \%$ & $2,8 \%$ \\
\hline Fonasa A,B & $51,2 \%$ & $38,4 \%$ & $26,0 \%$ & $50,5 \%$ \\
\hline Fonasa C,D & $22,2 \%$ & $19,9 \%$ & $23,8 \%$ & $22,1 \%$ \\
\hline Fonasa no sabe & $5,2 \%$ & $8,9 \%$ & $8,7 \%$ & $5,4 \%$ \\
\hline Isapre & $14,4 \%$ & $14,1 \%$ & $16,5 \%$ & $14,4 \%$ \\
\hline Otro & $2,8 \%$ & $1,9 \%$ & $0,6 \%$ & $2,8 \%$ \\
\hline No sabe & $1,9 \%$ & $2,9 \%$ & $2,3 \%$ & $2,0 \%$ \\
\hline
\end{tabular}

Fuente: Elaborado en base a estudio realizado por Cabieses et al., 2021b:19-33). 
Finalmente, la población venezolana si bien muestra niveles de pobreza menores que la población nacional (medida a través de ingreso), al medir la pobreza multidimensional, esta presenta un porcentaje mayor que la población local (21,4\% para venezolanos/as y 18,4\% para población nacional) (Cabieses et al., 2021b). Estos elementos son centrales para comprender los efectos que ha tenido la pandemia en este colectivo, tal como veremos más adelante.

\section{Abordar la pandemia a partir de la tensión entre el enfoque universalista y el excluyente}

Desde el 2000 Chile avanzó de manera significativa en la promoción del acceso a la salud para personas migrantes, a través del marco legal y de políticas públicas. En 2003 se tomó la medida de atención primaria y otorgamiento de una visa temporaria a la mujer embarazada inmigrante en situación irregular (Circular $\mathrm{N}^{\circ}$ 1179/2003) (Cabieses et al., 2021a). Los avances más recientes incluyen el Programa de Acceso a la Atención de Salud a Personas Inmigrantes ${ }^{3}$; el Piloto de Salud de Inmigrante del 2015 que buscó reducir brechas de atención de salud nivel primario y hospitalario; la disposición que asegura obertura bajo el tramo A de FONASA para las personas en situación irregular en igualdad de condiciones con la población local (Decreto N67 /2016), y finalmente, la Política de Salud de Migrantes Internacionales de 2017 (Ministerio de Salud s/f b).

Si bien estos avances fueron consolidando un consenso en torno a la importancia de garantizar el derecho a la salud para todas las personas, independiente de su situación migratoria, diversos estudios (Cabieses et al, 2021a) señalaban la existencia de barreras vinculadas con condiciones estructurales, así como de vulnerabilidades presentes en la población migrante, como por ejemplo, no estar inscrito en ninguno de los sistemas de salud disponible (público o privado), ausencia de recursos, escasa información respecto del funcionamiento del sistema y falta de documentos, entre otros. Estas barreras en el acceso no solo se mantuvieron, sino que en ocasiones impidieron o dificultaron en extremo la atención en salud y la prevención durante la pandemia. En este escenario, el Ministerio de Salud identificó a la población migrante como un grupo vulnerable e impulsó una agenda que buscaba reforzar su acceso y atención médica. Algunas de las medidas específicas implementadas fueron las siguientes (Cabieses et al., 2021a):

\footnotetext{
${ }^{3}$ Resolución Exenta No 1266 del 12 de diciembre de 2014
} 
- La Subsecretaría de Redes Asistenciales del Ministerio de Salud instó a identificar las poblaciones vulnerables que podrían presentar barreras de acceso, incluyendo a migrantes internacionales.

- Ministerio de Desarrollo Social dispuso de albergues en la región metropolitana para personas inmigrantes que se encontraran en situación de calle.

- La plataforma del gobierno "ChileAtiende" dispuso un área de información específica denominada "Coronavirus (COVID-19)" dirigida a migrantes internacionales en Chile.

- Incorporación de más de 530 profesionales de la salud de origen migrante cuyos títulos no estaban revalidados en Chile.

A estas medidas se suman propuestas por parte de la Mesa Social COVID-19 y del parlamento con atención específicamente en mujeres inmigrantes.

Una estrategia destacada ante el hacinamiento y las dificultades para cumplir con las medidas de aislamiento ha sido la implementación de residencias sanitarias, o lugares donde personas diagnosticadas con COVID-19 o cumpliendo con los criterios de caso sospechoso pueden aislarse en caso de no poder hacerlo en su hogar (Cabieses et al. 2021c). Según registros de la Secretaría Regional Ministerial (SEREMI) de Salud de la Región Metropolitana, durante el año 2020, 330 personas provenientes de Venezuela viviendo en la RM hicieron uso de este recurso frente a un contagio posible o confirmado.

Si bien el cuidado en residencias sanitarias por lo general ha sido bien evaluado, en el caso de la macrozona norte y de los usuarios migrantes en situación irregular, la falta de seguimiento y apoyo social al egresar de la residencia sanitaria ha provocado situaciones de calle en ciudades y pueblos fronterizos, incluidos niños, niñas, adolescentes y mujeres gestantes (Cabieses et al., 2021c). Esto releva la importancia de "crear y desplegar programas integrales de protección de la salud, atención de salud y acompañamiento a personas migrantes que están residiendo de manera accidental y desprotegida en la frontera, con adecuado financiamiento de emergencia socio-sanitaria" y de tomar en consideración la situación particularmente urgente de los niños, niñas y adolescentes no acompañados (Rechisam, 2021).

Finalmente, no se puede abordar la salud de las personas migrantes durante la pandemia por COVID-19 sin abordar la controversia frente al acceso al programa de vacunación. El 10 de febrero 2021 se informó de la decisión del gobierno chileno de no vacunar a personas migrantes internacionales con visa de turista o en situación irregular, a través de la Resolución Exenta 1138 (136). Organizaciones sociales y académicos del área de la salud y de las ciencias sociales indicaron que esta medida atentaba contra el derecho a la salud (que, como hemos visto, se había logrado garantizar a través de los años). Atentaba, además, contra la salud pública, puesto que no vacunar a una parte implicaba un riesgo a la 
totalidad de la población. El 26 de marzo 2021, el Ministerio de Salud publicó el Ord. 1118 que clarificaba que la vacuna estaría disponible para todos/as, incluidas las personas en situación migratoria irregular (El Mostrador, 2021).

En esta controversia observamos cómo el principio universal de derecho a la salud se logró imponer por sobre aquel que excluye de este derecho a un grupo determinado.

Desde el lugar de la política migratoria, la llegada del COVID-19 generó una serie de medidas por parte de los gobiernos de la región latinoamericana. Una de ellas fue el cierre de las fronteras, planteando un escenario de inmovilidad a nivel global sin registro en nuestra historia. Las consecuencias económicas y la pérdida de fuentes laborales comenzaron a ocasionar estragos en la población, incluidas las personas inmigrantes. Si bien esta medida en específico se tomó a raíz de la pandemia, el cierre de la frontera se convirtió en una figura que representa el corolario de una serie de medidas que se han tomado en el pasado, orientadas a restringir determinadas movilidades a través del incremento en los requisitos de ingreso, visas de carácter temporal, incremento en expulsiones, y crecientes dificultades de orden administrativo para obtener las visas.

Dentro de las medidas adoptadas con anterioridad al 2020, y que afectaron el ingreso de personas venezolanas, se encuentra la Visa de Responsabilidad Democrática (VRD) (2018) y el establecimiento de la Visa Consular de Turismo (VCT) (2019) (Freier, 2018; Gandini et al., 2019; Stefoni; Brito, 2019). Ambas han sido duramente criticadas debido a la alta tasa de rechazo que tienen para quienes postulan. El reciente informe del Servicio Jesuita Migrante (2021) elaborado en base a datos solicitados por Ley de Transparencia ${ }^{4}$, señala que en el caso de la VRD sólo el $27 \%$ de todas las solicitudes han sido otorgadas, mientras que, en el caso de las visas consulares de turismo, el $21 \%$ lo fueron.

Tabla 2 - Visas Responsabilidad Democrática y Visas Consulares de Turismo

\begin{tabular}{|c|c|c|}
\hline & $\begin{array}{l}\text { Visa Responsabilidad } \\
\text { Democrática }\end{array}$ & $\begin{array}{l}\text { Visas consulares de turismo } \\
\text { personas venezolanas }\end{array}$ \\
\hline Cerradas/Rechazadas & $164.783(72 \%)$ & $36.125(81 \%)$ \\
\hline En trámite & 2.190 & $(2 \%)$ \\
\hline Otorgadas & $60.650 \quad(27 \%)$ & $9.295 \quad(21 \%)$ \\
\hline Total de solicitudes & $227.623(100 \%)$ & $44.785 \quad(100 \%)$ \\
\hline
\end{tabular}

Fuente: Servicio Jesuita a Migrantes (2021). Migración en Chile. Anuario 2020. Medidas migratorias, vulnerabilidad y oportunidades en un año de pandemia. Informe elaborado en base a datos solicitados por transparencia a la Policía de Investigaciones (PDI).

\footnotetext{
${ }^{4}$ Ley de transparencia (Ley $\mathrm{N}^{\circ}$ 20.285/2009) reconoce a todas las personas su derecho de acceso a la información pública y establece el deber de los organismos públicos de recibir las solicitudes y entregar la información, salvo que exista secreto o reserva.
} 
Por otra parte las solicitudes de refugio también han sido sistemáticamente rechazadas. De acuerdo con el mismo informe, se formalizaron 1.629 de estas solicitudes, sin embargo, solo se reconocieron 7 casos (SJM, 2021). Las bajísimas tasas de entrega de las VRD y de VCT, así como el rechazo de las solicitudes de refugio, generaron en 2020 un incremento sin precedentes de cruces irregulares, tal como lo indica la tabla $\mathrm{N}^{\circ} 3$.

En lo que concierne a los migrantes venezolanos, se pasó de 101 casos en 2018, a 3.333 en 2019, y 12.935 en 2020, evidenciando la magnitud de la crisis humanitaria y las consecuencias de una política de cierre de fronteras.

Tabla 3 - Ingresos por pasos no habilitados entre 2010 y enero 2021, según año y nacionalidad

\begin{tabular}{|c|c|c|c|c|c|c|c|c|c|c|c|c|c|}
\hline País & 2010 & $\begin{array}{l}201 \\
1\end{array}$ & 2012 & 2013 & 2014 & 2015 & 2016 & 2017 & 2018 & 2019 & 2020 & $\begin{array}{c}a \\
\text { enero } \\
2021\end{array}$ & Total \\
\hline Bolivia & 161 & 486 & 568 & 271 & 206 & 204 & 318 & 300 & 322 & 755 & 844 & 451 & 4.435 \\
\hline Colombia & 80 & 222 & 312 & 843 & 992 & 348 & 234 & 253 & 270 & 439 & 742 & 130 & 4.735 \\
\hline Cuba & 6 & 30 & 23 & 11 & 9 & 24 & 38 & 715 & 3.574 & 1.448 & 449 & 20 & 6.327 \\
\hline Haití & 2 & 12 & 4 & 1 & 11 & 15 & 31 & 12 & 19 & 644 & 1.089 & 112 & 1.840 \\
\hline Perú & 132 & 107 & 90 & 107 & 105 & 111 & 145 & 70 & 120 & 117 & 332 & 40 & 1.436 \\
\hline Rep.Dom. & 4 & 12 & 32 & 297 & 665 & $\begin{array}{l}1.01 \\
7\end{array}$ & $\begin{array}{l}1.81 \\
1\end{array}$ & 1.453 & 1.785 & 1.190 & 286 & 27 & 8.552 \\
\hline Venezuela & 0 & 0 & 2 & 1 & 1 & 1 & 11 & 9 & 101 & 3.333 & 12.935 & $\begin{array}{l}3.46 \\
3\end{array}$ & $\begin{array}{l}16.39 \\
4\end{array}$ \\
\hline Otros & 30 & 53 & 78 & 133 & 108 & 59 & 77 & 93 & 119 & 122 & 171 & 28 & 1.043 \\
\hline Total & 415 & 922 & 1.109 & 1.664 & 2.097 & 1.779 & 2.665 & 2.905 & 6.310 & 8.048 & 16.848 & 4.271 & 44.762 \\
\hline
\end{tabular}

Fuente: Servicio Jesuita a Migrantes (2021) Migración en Chile. Anuario 2020. Medidas migratorias, vulnerabilidad y oportunidades en un año de pandemia. SJM. Informe elaborado en base a datos solicitados por transparencia a la Policía de Investigaciones (PDI).

En este escenario, durante 2020 se tomaron nuevas medidas que buscaron controlar aún más el ingreso de población inmigrante. Estas medidas utilizaron indistintamente el argumento sanitario y el control de ingresos irregulares en la frontera norte. Entre las medidas implementadas, encontramos:

- Cierre frontera. El 17 de marzo de 2020 el gobierno dispone el cierre temporal de lugares habilitados para ingreso y egreso de extranjeros debido a la presencia de casos de COVID-19. El 23 de noviembre del mismo año se anunció la apertura del aeropuerto internacional ubicado en Santiago, pero se mantuvo el cierre de las fronteras terrestres. El 5 de abril de 2021, producto del incremento en las tasas de contagio, el aeropuerto se vuelve a cerrar para ciudadanos chilenos y extranjeros y sólo se establece la excepción por motivos urgentes, de carácter humanitario o tratamientos médicos.

- Suspensión informática de la VRD. El 13 de noviembre de 2020 la Cancillería suspendió la VRD que había establecido en 2018, argumentando que el cierre de fronteras y la crisis sanitaria habían generado que los plazos establecidos para finalizar el proceso administrativo se excedieran, y por tanto, se rechazaran las solicitudes (El mercurio, 13 noviembre 2020). 
- Plan Colchane. Las crecientes dificultades de orden administrativo y el cierre de las fronteras terrestres generaron un incremento en el número de cruces de manera irregular en el paso de Colchane, en la frontera Chile-Bolivia (Tabla N³). Ello llevó a que el gobierno, en febrero 2021, buscara controlar la situación a través de una serie de medidas enmarcadas en el denominado "Plan Colchane". Entre estas medidas destaca un plan de expulsión -previa licitación de vuelos comerciales para llevarlo a cabo- de personas que fueran sorprendidas cruzando la frontera de manera irregular. El plan también implicó una solicitud a las autoridades políticas y policiales de Perú y Bolivia para que establecieran controles más estrictos, y un programa de difusión para "advertir las medidas adoptadas por Chile". Este Plan fue liderado por el Ministerio de Relaciones Exteriores, Ministerio del Interior y Ministerio de Defensa (Rivera V, La Tercera, 11 marzo 2021).

- Militarización de la frontera. En el marco del Plan Colchane, el 4 de febrero de 2021 el gobierno de Chile, a través del decreto N265, autorizó a las Fuerzas Armadas para que asistieran a la policía para resguardar las fronteras a través de uso de tecnología y patrullajes (Ministerio de Defensa, diario oficial 4 febrero 2021).

- Programa de retorno "voluntario". Como medida para facilitar el retorno de personas migrantes que desearan hacerlo, el gobierno estableció un programa denominado "retorno humanitario" que requería, para ser efectivo, que la persona se comprometiera a no regresar al país en un plazo de 9 años. La Corte Suprema acogió un recurso de amparo presentado por 26 ciudadanos colombianos quienes recurrieron en contra de dicho plan. La Corte falló a favor de las personas colombianas y estableció que era improcedente el requerimiento de prohibición de ingreso (Leslie Araya, La Tercera, 4 julio 2020).

- Expulsiones. Durante 2020 las expulsiones de ciudadanos migrantes tuvieron una amplia difusión en la prensa. Sin embargo, los datos aportados por el informe del servicio Jesuita Migrante indican una disminución en el número de expulsiones en relación a 2019. Una de las razones posibles de esta caída sería la propia pandemia. La siguiente tabla también entrega un dato preocupante, esto es la diferencia entre las expulsiones decretadas y las ejecutadas. Ello daría cuenta de un creciente número de personas que estarían en el territorio sin ningún tipo de protección.

Tabla 4 - Expulsiones decretadas y ejecutadas

\begin{tabular}{|l|l|l|l|}
\hline & 2018 & 2019 & 2020 \\
\hline Expulsiones decretadas & 5.095 & 8.445 & 5.185 \\
\hline Expulsiones ejecutadas & 2.052 & 2.232 & 1.470 \\
\hline
\end{tabular}

Fuente: Servicio Jesuita a Mgrantes 2021 Migración en Chile. Anuario 2020. Medidas migratorias, vulnerabilidad y oportunidades en un año de pandemia. Informe elaborado en base a datos solicitados por transparencia a la Policía de Investigaciones (PDI).

En tanto, el Departamento de Extranjería tomó algunas medidas para facilitar la tramitación de las visas, como por ejemplo:

- Extensión de vigencia de la cédula de identidad para extranjeros (Decreto N³4, 2020 Ministerio de Justicia y Derechos Humanos).

- Digitalización de los trámites con el objeto de reducir la presencia de público en las oficinas de Extranjería y evitar la exposición al virus. Implementación de un certificado de visado de residente para quienes no hayan podido estampar la visa otorgada, con vigencia de 6 meses. 
- Reducción de requisitos para solicitantes de permanencia definitiva, nacionalización y prórroga de visa temporaria.

Sin embargo, estas medidas no han sido suficientes para agilizar los ya demorados trámites migratorios. En la encuesta realizada a población venezolana (Stefoni et al. 2021) el $68,2 \%$ señala que la pandemia afectó la tramitación de sus respectivas visas.

Una segunda controversia entre el enfoque universal y el securitarista se produjo precisamente en la localidad de Colchane y en la ciudad de Iquique (a la que llegan las personas que cruzan por el paso fronterizo entre Bolivia y Chile en los territorios nortinos del país). Al entrar al territorio chileno, toda persona debe cumplir una cuarentena preventiva. En el caso de quienes ingresan de manera irregular, la posibilidad de realizar la cuarentena en la ciudad de Iquique en las residencias sanitarias disponibles quedó condicionada a realizar una autodenuncia por ingreso por paso no habilitado ante la Policía de Investigaciones (PDI). Esta situación constituye un condicionante al derecho a acceder a los servicios de salud dispuestos para el control del COVID-19 (Cabieses et al. 2021c). Más aún, esta autodenuncia es un documento que permite contar con un registro de todos quienes ingresaron de manera irregular, y si bien las personas que lo hicieron lo interpretan como un paso que podría llevar a un posterior proceso de regularización, las autoridades han sido enfáticas en señalar que se expulsará a todos quienes hayan ingresado de esta manera. En este caso observamos como el criterio sanitario que sostiene el enfoque universal, quedó supeditado al enfoque securitarista.

\section{Efectos de ambas aproximaciones en el tratamiento de la pandemia en la población venezolana}

Al 9 de abril 2021, poco más de un año después del primer caso detectado en Chile, la pandemia había cobrado 24.108 vidas a nivel nacional según el Ministerio de Salud (Ministerio de salud s/f, a) además de la crisis sanitaria, la pandemia desencadenó una crisis social, con precarización y pérdida de empleo e ingresos, acompañados de un limitado apoyo institucional. Si bien la crisis afecta tanto a la población local como a la migrante, ésta se enfrenta a dificultades particulares vinculadas con el estatus migratorio, la falta de redes de apoyo y la precariedad de la vivienda, la que se expresa en altas tasas de hacinamiento y riesgo de desalojo repentino y arbitrario (Cabieses, 2020).

Según los datos disponibles, hasta el 30 de julio 2020, del total de 376.228 casos notificados de COVID-19, un 9,0\% $(\mathrm{n}=34.016)$ correspondieron a personas migrantes internacionales (Cabieses et al., 2021d). Según la misma fuente y a la misma fecha, la 
proporción de personas migrantes notificadas fue mayor en las regiones de Tarapacá $(21,9 \%)$, Antofagasta (17,3\%) y la Región Metropolitana (10,0\%). Asimismo, se reportó que el 74,6\% de personas migrantes notificadas eran adscritas a FONASA, y el 12,8\% no reportó adscripción a cobertura de salud. Finalmente, un 4,4\% de las personas migrantes diagnosticadas con COVID-19 se hospitalizó y 184 fallecieron, la mayoría de las cuales del sexo masculino.

A comienzos de la pandemia el equipo de Cabieses realizaron una encuesta de opinión y entrevistas cualitativas a la población migrante y se les consultó si se sentían preparadas para enfrentar la crisis social y sanitaria (ver apartado metodología para especificaciones de la muestra). El $65 \%$ contestó que no se sentía preparado y los principales factores asociados fueron el ser mujer, no haber sostenido una cuarentena voluntaria, no tener cobertura de salud o tener cobertura de salud pública y calificar la información recibida de las autoridades sanitarias y los equipos de salud como mala o muy mala (Cabieses, Darrigrandi, et al., 2020). En lo que concierne las vulnerabilidades particulares frente al contagio y las estrategias de cuidado durante la pandemia, destaca el cumplimiento estricto de las medidas de autocuidado recomendadas tales como el uso de mascarilla, distanciamiento físico y limitación de participación en reuniones sociales. Sin embargo, los que reportaron no haber cumplido con las medidas de cuarentena lo relacionaron con la necesidad económica de salir a trabajar, especialmente en el caso de trabajadores del sector informal (Cabieses et al., 2021d):

\footnotetext{
"Yo creo que, que todos nos sentimos así como, como por un lado vulnerable porque uno no sabe cuando le puede tocar, porque eso es algo que tarde o temprano nos va a dar. Porque uno no sabe si sale a la esquina, o pase alguien que, porque yo vivo en un cuarto de dos por tres, o sea mi cuarto es súper pequeño y vivimos los cinco, o sea yo se lo puedo mostrar, de este tamaño es la habitación, lo que esta ahí esa es la habitación. Entonces como vivimos varios y algunas personas como no tienen niños, dicen bueno soy yo y lo que le pase a los demás con tal que yo me cuide, esta bien." (Hombre venezolano_Arica_1).
}

"Mandábamos a comprar todo, nos lo traían hasta la puerta de la casa, el tema de contaminarlo y todo, pero ya cuando dejaron a empezar salir ya como que, para verme más relajada y con libertad salía yo misma, pero eso si me cuido, soy extrema con los cuidados porque, como yo digo, si yo me enfermo yo los enfermo a ellos y es terrible." (Mujer venezolana_Santiago_3).

"Y cuando empezó duré dos o tres semanas sin salir entonces no, yo tengo que trabajar pues, tengo que pagar arriendo, la comida de las niñas, los pañales, leche no, ya no toman leche pero, pero todo eso acá en la casa no hacer nada. Como no estamos legal no tenemos un sustento de nada, que nos vayan a dar algo, porque yo trabajo en construcción y me dicen: bueno esta semana no vas a trabajar y yo quedó ahí en el aire." (Hombre venezolano_Arica_2). 
El estudio realizado por Stefoni et al (2021) entrega información sobre algunos de los efectos que ha tenido la pandemia en la población venezolana, específicamente en términos del empleo y la obtención de sus documentos. Los datos que entrega la encuesta aplicada indican que en plena pandemia el $61 \%$ de las personas venezolanas encuestadas se encontraba trabajando, mientras que el $27 \%$ estaba buscando trabajo y sólo el $8 \%$ no estaba trabajando y no estaba buscando.

Por otra parte, el $36 \%$ señala haber perdido su empleo producto de la pandemia, mientras que el $54 \%$ lo mantuvo y $10 \%$ cambió de empleo. Al consultar si la cantidad de trabajo había variado durante la pandemia, el 52\% señala que había disminuido, mientras que para el 30\% se mantuvo igual, y para el $18 \%$ había aumentado. Un elemento importante son las extensas jornadas de trabajo, tal como lo indica la siguiente tabla. En ella, vemos que $59,4 \%$ de los encuestados declara trabajar más de 40 horas semanales.

Tabla 5 - Jornada laboral

\begin{tabular}{|l|l|}
\hline \multicolumn{2}{|l|}{ ¿Cuántas horas laborales remuneradas trabajó la semana pasada? } \\
\hline Menos de 15 & $21(10,1 \%)$ \\
\hline Entre 15 y 22 & $9(4,3 \%)$ \\
\hline Entre 20 y 30 & $11(5,3 \%)$ \\
\hline Entre 30 y 40 & $43(20,8 \%)$ \\
\hline Más de 40 & $123(59,4 \%)$ \\
\hline
\end{tabular}

Fuente: Stefoni et al. (2021) Estudio Inserción sociolaboral de la población venezolana en Chile. Informe financiado por Fundación Konrad Adenauer.

Por otra parte, la mayoría de la población venezolana consultada en este estudio contaba con un contrato de trabajo $(83,3 \%)$, cuestión que coincide con la información entregada en la encuesta CASEN 2017 (señalada más arriba). El elevado porcentaje de migrantes con contrato, se debe muy probablemente a la necesidad de contar con este documento para poder dar inicio al proceso de regularización, es decir, solicitar la visa temporal y luego la definitiva.

Tabla 6- Contrato laboral

\begin{tabular}{|l|l|}
\hline \multicolumn{2}{|l|}{ ¿En su empleo principal, usted tiene un contrato escrito? } \\
\hline Si & $\begin{array}{l}179 \\
(83,3 \%)\end{array}$ \\
\hline No & $\begin{array}{l}36 \\
(16,7 \%)\end{array}$ \\
\hline
\end{tabular}

Fuente: Stefoni, et. al (2021) Estudio Inserción sociolaboral de la población venezolana en Chile. Informe financiado por Fundación Konrrad Adenauer. 
Uno de los aspectos más problemáticos junto con la dimensión laboral, son las dificultades de acceso a las prestaciones sociales entregadas por el Estado y los municipios. La siguiente tabla da cuenta del poco acceso que ha tenido este grupo a las distintas ayudas entregadas por el Estado. Sólo en el caso del retiro del 10\% de los Fondos Previsionales ${ }^{5}$, el $58 \%$ de las personas venezolanas consultadas señaló que había podido realizarlo. Del total de encuestados, el 35\% indicó que había recibido una caja de alimentos, y un 20\% indicó que había accedido al seguro de cesantía. El resto de los programas de ayuda han tenido una incidencia muy baja en este colectivo.

Tabla 7 - Apoyos durante la pandemia

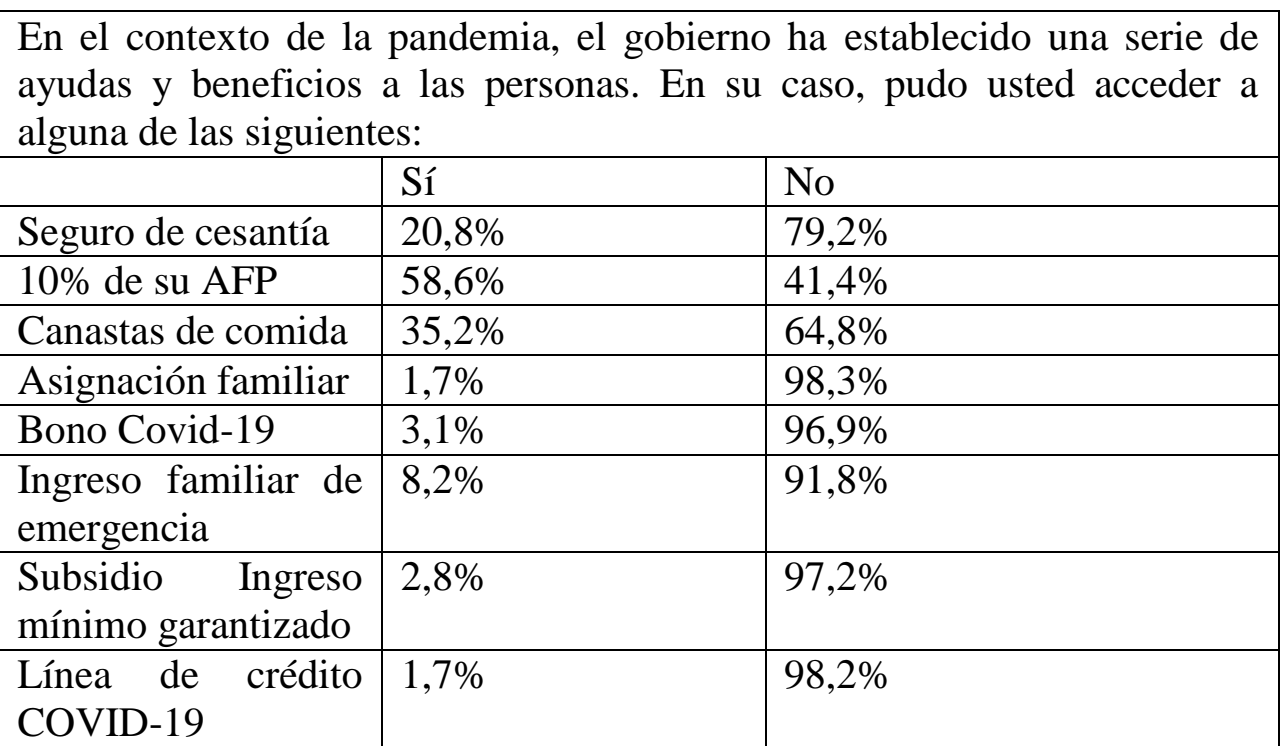

Fuente: Stefoni, et al. (2021) Estudio Inserción sociolaboral de la población venezolana en Chile. Informe financiado por Fundación Konrad Adenauer.

La principal razón y que actúa nuevamente como barrera de acceso es no contar con el RUT (el carné personal de identidad chileno) vigente, necesario para acceder a cada uno de estos programas. De hecho, en la encuesta realizada, el 50\% de los encuestados señalaron tener un RUT vencido, mientras que un $13 \%$ no contaba con este documento.

\footnotetext{
${ }^{5}$ En Chile existe un sistema privado de administración de los fondos previsionales (AFP). Durante la pandemia se tramitó una ley que permitió el retro anticipado del 10\% de dichos fondos a todos los cotizantes. A la fecha se ha aprobado el retiro del $30 \%$ de dichos fondos.
} 


\section{Gráfico 4 - Posee RUT}

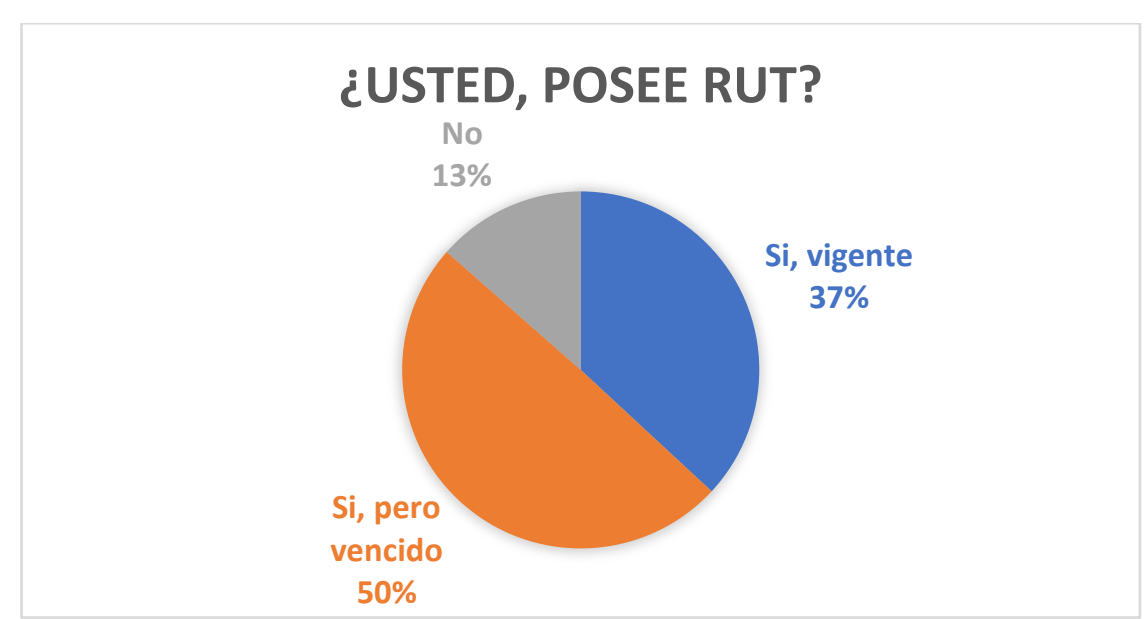

Fuente: Stefoni, et al. (2021) Estudio Inserción sociolaboral de la población venezolana en Chile. Informe financiado por Fundación Konrad Adenauer.

Un funcionario de una Municipalidad de la región de Los Lagos (en el sur del país) indica que quienes no cuentan con este documento, no pueden acceder a las cajas de alimentos que entregadas por la municipalidad (Stefoni et al., 2021):

Entrevistador: ¿Y en el caso de los que no tienen Rut vigente no lo pueden atender? Entrevistado 2: Si no tiene Rut vigente, no pueden optar a nada, si tienen el Rut vigente ingresan en el registro social de hogares y con eso ya pueden solicitar alimentos, pueden solicitar remedios (Ruth_entrevista No4_Osorno/Municipalidad_ 02.11.2020).

Un segundo factor es el desconocimiento de la información y del funcionamiento del sistema para acceder a estos beneficios. Este desconocimiento se profundiza al no contar con personal en las reparticiones públicas que oriente a la población migrante, situación que los deja en una sensación de completo abandono, tal como indica el siguiente entrevistado:

Mira, hubo un detalle que pasó cuando comenzó la cuarentena que fue que cerraron casi, las gobernaciones estuvieron cerradas y hubo un cambio de gobernador también. Y todo eso movió la ficha a tal punto que eso estuvo cerrado y uno trataba información y nos decían es un correo electrónico. Y el bendito correo electrónico nadie respondía. Entonces estábamos al punto que estuvimos incomunicados, y lo que hice yo fue que me reuní con la señora [encargada de la situación de las personas migrantes en otra comuna] y toda la información de lo que necesitarán acá lo canalicé con ella porque ella conoce cómo es el proceso y entonces tuvimos que recurrir a una tercera persona para que nos ayudará a solucionar las dudas porque acá en la ciudad había poca disposición

Entrevistador: ¿Poca disposición desde las autoridades?

Entrevistado: Sí, casi que puertas cerradas, ustedes no importan o sea quedamos a la deriva y por eso fue que yo tuve que activar unos mecanismos de vamos a consultar a alguien en otra región, donde personas que sí están abiertas a colaborar nos colabore (Joaquín_entrevista 2_Osorno_02.11.2020). 
Por otra parte, los discursos securitistas que han dominado la agenda pública en materia migratoria (Brandariz; Dufraix; Quinteros, 2018; Liberona; López, 2018; Ramos; Tapia, 2019; Stefoni; Brito, 2019) impactan en la percepción que los propios venezolanos y venezolanas tienen sobre sus derechos y en particular el derecho a la salud. Las siguientes citas dan cuenta de ello, en el marco de la atención de salud (Cabieses et al., 2021d):

\footnotetext{
"Es que realmente el miedo es por si, bueno no sé, qué te vamos a decir, bueno yo lo voy a decir. El tema es que como somos extranjeros obviamente existe el miedo a la xenofobia y esto, el miedo que tenemos nosotros a que no nos vayan a dar un servicio por ser extranjeros, porque no somos monedas de oro, los venezolanos estamos muy rallados entonces, claro es el miedo a ingresar a un sistema y bueno nada, te deje allí porque eres extranjero y la prioridad es para los chilenos. Y entonces claro a mi eso es lo que más me preocupa realmente y en este hilo de ideas conversando con ella también se que eso es lo que le preocupaba porque me lo dijo muchas veces" (Mujer venezolana_Santiago_2).

"Lo primero que preguntó era si éramos extranjeros, yo le dije que sí pero que mi bebé tenia nacionalidad chilena por mi esposo, y yo me imagino que por eso no nos trato tan bien como debería, porque éramos extranjeros porque a lo mejor era xenofóbico, no sé.” (Mujer venezolana_Arica_1).

“Con mi hijo pequeño me pasó que como él es asmático, una noche me tocó llevarlo y no me lo quisieron atender. Me lo atendieron como por no hacerme un desaire, una grosería pero me dijeron que para la próxima vez no me lo podían atender porque como todavía no tenia documento chileno (...) Me dijeron, lo vamos a atender como decir una caridad, un favor, como por hacer un favor pero ellos no tenían permitido atender gente si entraba como turista al país, tenían que irse al sistema privado" (Mujer venezolana_Santiago_1).
}

\section{Conclusiones}

Los actuales movimientos migratorios han puesto en jaque la concepción clásica de pertenencia al Estado-nación en base a la nacionalidad (Ong, 2006; Sassen, 2002). Lo anterior develó la urgencia de avanzar hacia otros sistemas que aseguren la pertenencia plena al Estado y con ello el acceso a derechos en igualdad de condiciones que la población local. Sin embargo, el enfoque securitista y el actual régimen migratorio y de fronteras que ha sostenido las medidas y políticas migratorias introduce un criterio de exclusión de derechos de aquellas personas que no tienen documentos. En Chile el actual cierre de fronteras asociado a la pandemia, el consecuente aumento en ingreso irregular, las demoras en la entrega de las visas y el discurso criminalizante de la política migratoria profundizan la precariedad de muchas personas migrantes, lo que se transforma en una nueva barrera de acceso al servicios de salud, pese a lo que establece el decreto 67 y que garantiza el acceso a personas en situación irregular. 
A lo anterior se suman las barreras estructurales de acceso a la salud entre los que no están adscritos a ningún sistema de salud (público o privado), dificultad en el acceso a la información, no contar con recursos para atenderse de manera privada, temor a ser rechazado en los consultorios o a ser discriminadas/os en los centros de salud. Asimismo, cabe señalar que, en el caso de las personas migrantes provenientes de Venezuela, surgen desafíos específicos. Estos se vinculan, por una parte, con el desplazamiento forzoso y el refugio, sobre todo en el ámbito de la salud mental. Por otra parte, se refieren también a las barreras de regularización ya sea por ingreso por paso no habilitado o por otras dificultades administrativas, las cuales a su vez limitan el acceso al empleo formal, lo cual puede también repercutir en la salud de las personas, especialmente en el contexto de la pandemia.

Las cuarentenas como medida de prevención de la expansión del virus plantearon una encrucijada muy compleja, puesto que un amplio sector de la sociedad no tiene las condiciones materiales para quedarse en casa, por lo que tienen que salir a trabajar para poder comer, arriesgando su salud y la posibilidad de que aumente la circulación del virus. En el caso de Chile, la sobrerrepresentación que los extranjeros tienen en el sector informal de la economía y la ausencia de redes de apoyo, determinó que sea uno de los grupos sociales más perjudicados. A ello se suma la situación de irregularidad de muchos inmigrantes, lo que les dificulta el acceso a los beneficios y ayudas sociales entregados por el gobierno central y los gobiernos locales, así como los altos niveles de hacinamiento y precariedad en la vivienda.

En tal sentido, Chile ha enfrentado un complejo escenario de migración en pandemia por COVID-19. Esto es reflejo de múltiples crisis simultáneas que se están enfrentando en la región. Entre ellas, se identifica la crisis migratoria intrarregional marcada por el éxodo humanitario de venezolanos dentro del cono sur, las crisis sociales y política en distintos países llamando desde las bases comunitarias a mayor justicia social y protección social, las crisis culturales y sociales marcada por la xenofobia y el desprecio a las múltiples "otredades" que cohabitan en los países desde sus grupos más conservadores, por mencionar algunos principales. En este complejo contexto, el enfoque securitista ha predominado por encima del universalista propio de la historia de la salud pública de Chile y que le ha permitido distinguirse entre otras naciones por sus excelentes indicadores globales de salud. Es urgente reflexionar sobre los orígenes de un enfoque y de otro, pero sobre todo discutir de manera informada acerca de los efectos a largo plazo de una y de otra para Chile. Este debate podría invitarnos a repensar qué tipo de país queremos ser, compartiendo diversidad de miradas en forma respetuosa e inclusiva. También se haría urgente reforzar un trabajo intersectorial, en el cual se deben tomar en cuenta todos los determinantes sociales de la salud y otros factores 
estructurales y circunstanciales que puedan constituir una barrera al derecho a la salud de las personas venezolanas en Chile, de cara a la evidencia disponible en la actualidad y con miras a un mayor porvenir y bienestar para todos y todas en nuestro país, sin que "nadie quede atrás".

\section{Referencias}

ACOSTA, Diego; FREIER, Feline (2015), "Discursos y políticas de inmigración en Sudamérica: ¿Hacia un nuevo paradigma o la confirmación de una retórica sin contenido?". Revista Interdisciplinar da Mobilidade Humana, v. 23, n. 44, pp. 171-189 [Consult. 04-07-2021]. Disponible en doi.org/10.1590/1980-85852503880004411

BAUBÖCK, Rainer (2006), Migration and Citizenship. Legal Status, Rights and Political Participation. Amsterdam, University Press IMISCOE Reports.

BOJORQUEZ, Ietza; CABIESES, Báltica; AROSQUIPA, Carlos; ARROYO, Juan; NOVELLA, Andrés; Knipper, Michael (2021), "Migration and health in Latin America during the COVID-19 pandemic and beyond". The Lancet, v. 397, n. 10281, pp. 1243-1245.

BRANDARIZ, José A.; DUFRAIX, Roberto; QUINTEROS, Daniel (2018), "La expulsión judicial en el sistema penal chileno: ¿Hacia un modelo de Crimmigration?” Política criminal, v.13, n. 26, pp. 739-770 [Consult. 04-07-2021]. Disponible en http://dx.doi.org/10.4067/S071833992018000200739

BRUBAKER, Rogers (2010), "Migration, membership and the Modern Nation-State: Internal and External Dimensions of the Politics of Belonging". Journal of Interdisciplinary History, v. 41, n.1, pp. 61-78 [Consult. 04-07-2021]. Disponible en https://www.jstor.org/stable/40785026

CABIESES, Báltica (2020), Encuesta sobre COVID-19 a Poblaciones Migrantes Internacionales en Chile: Informe de Resultados Completo. Universidad del Desarrollo. 228 p. [Consult. 04-07-2021. Disponible en http://hdl.handle.net/11447/3267

CABIESES, Báltica; DARRIGRANDI, Florencia; BLUKACZ, Alice; OBACH, Alexandra; SILVA, Claudia (2021a), Migrantes venezolanos frente a la pandemia de COVID-19 en Chile: Factores asociados a la percepción de sentirse preparado para enfrentarla [Consult. 04-07-2021]. Disponible en https://repositorio.cepal.org//handle/11362/46554

CABIESES, Báltica, LARENAS, Daniel, OYARTE, Marcela; DARRIGRANDI, Florencia (2021b), Proyecto de Sistematización de la Respuesta Sanitaria de los Países Andinos ante la Migración Venezolana. El caso de Chile. Universidad del Desarrollo, Universidad Cayetano Heredia, UK Research and Innovation, Universidad Javeriana (en imprenta).

CABIESES, Báltica; OBACH, Alexandra; BLUKACZ, Alice; CARREÑO, A., LARENAS, Daniel; MOMPOINT, Emanuel (2021c), Migrantes Internacionales en Residencias Sanitarias en Chile durante la Pandemia COVID-19: Hacia una Respuesta Ética en Emergencias Sanitarias. Organización Mundial de la Salud, 183, p. 
CABIESES, Báltica; OBACH, Alexandra; BLUKACZ, Alice; VICUÑA, José T.; CARREÑO, Alejandra; STEFONI, Carolina, PEREZ Claudia; AVARIA, Andrea; OYAERTEQ, Marcela; RADA, Isabel; SCHNEIDER, Stephen (2021d), Vulnerabilidades y recursos de comunidades migrantes internacionales en Chile para enfrentar la pandemia SARS-CoV-2: Construyendo estrategias diferenciadas desde la interculturalidad.Informe de resultados generales y recomendaciones para la política sanitaria. Universidad del Desarrollo. 206 p. [Consult. 9-42021]. Disponible en http://hdl.handle.net/11447/3842

MINISTERIO DE SALUD. (s/f a) Casos confirmados en Chile COVID-19 [Consult. 9-4-2021]. Disponible en https://www.minsal.cl/nuevo-coronavirus-2019-ncov/casos-confirmados-en-chilecovid-19/

MINISTERIO DE SALUD ( $\mathrm{s} / \mathrm{f}$ b). Salud del Inmigrante [Consult. 22-4-2020]. Disponible en https://www.minsal.cl/salud-del-inmigrante/

CASEN (2017). Inmigrantes. Síntesis de resultados. CASEN 2017. Santiago, Ministerio de Desarrollo Social.

CASTLES, Stephen; MILLER, Mark (2007), La era de las migraciones: Movimientos internacionales de población. México, Universidad Autónoma Metropolitana.

DECRETO 265 (9 julio 2021) Autoriza colaboración y delega en el Ministerio de Defensa Nacional las Facultades en Materia que Indica [Consult. 04-07-2021]. Disponible en https://www.bcn.cl/leychile/navegar?idNorma=1155524\&idParte=10199226

DE GENOVA, Nicholas (2013), "Spectacles of migrant 'illegality': The scene of exclusion, the obscene of inclusion". Ethnic and Racial Studies.v. 36. n. 7. pp. 1180-1198 [Consult. 04-07-2021]. Disponible en https://doi.org/10.1080/01419870.2013.783710

DE GENOVA, Nicholas (2015), "Extremities and regularities. Regulatory regimes and the spectacle of immigration enforcement" in Y. Jansen; R. Celikates, J. De Bloois (Eds.), The irregularization of migration in contemporary Europe. Detention, deportation, drowning. London, Rowman \& Littlefield International.

DE LUCAS, Javier (2003), "Inmigración y globalización. Acerca de los presupuestos de una política de inmigración". Redur, n. 1. pp. 43-70 [Consult. 04-07-2021]. Disponible en https://doi.org/10.18172/redur.3830

DE LUCAS, Javier (2009), "Inmigración, diversidad cultural, reconocimiento político". Papers: revista de sociología, n. 94, pp.11-27 [Consult. 04-07-2021]. Disponible en https://doi.org/10.5565/rev/papers/v94n0.687

DOMENECH, Euardo (2009), "La visión estatal sobre las migraciones en la Argentina reciente. De la retórica de la exclusión a la retórica de la inclusión" in E. Domenech (Ed.), Migración y política: El Estado interrogado. Procesos actuales en Argentina y Sudamérica. Córdoba, Argentina. Universidad Nacional de Córdoba.

El Mercurio (13 de noviembre de 2020). Suspenden visas de responsabilidad democrática para venezolanos: Cancillería afirma que es un reinicio [Consult. 20-7-2021]. Disponible en https://www.emol.com/noticias/Nacional/2020/11/13/1003665/Suspenden-visas-ResponsabilidadDemocratica-venezolanos.html

FERRAJOLI, Luigi (2008), "Universalismo de los derechos fundamentales y multiculturalismo". IUS. Revista del Instituto de Ciencias Jurídicas de Puebla, n. 22. pp. 35-45. 
FREIER, Feline; Parent, Nicolas (2018), "A South American Migration Crisis: Venezuelan outflows test neighbors' hospitality". Migration Policy Institute. Disponible en https://www.migrationpolicy.org/article/south-american-migration-crisis-venezuelan-outflows-testneighbors-hospitality

FREIER, Feline; VERA, Marcia (2021), “COVID-19 and Immigrants' Increased Exclusion: The Politics of Immigrant Integration in Chile and Peru". Frontiers in Human Dynamics, n. 3 [Consult. 04-07-2021]. Disponible en https://doi.org/10.3389/fhumd.2021.606871

GANDINI, Luciana; LOZANO, Fernando; PRIETO, Victoria (2019), Crisis y migración de población venezolana. Entre la desprotección y la seguridad jurídica en Latinoamérica. México. Universidad Nacional Autónoma de México.

GHOSH, Bimal (2008), "Derechos humanos y migración: El eslabón perdido". Migración y Desarrollo, n. 10, pp. 37-63 [Consult. 04-07-2021]. Disponible en https://www.redalyc.org/articulo.oa?id=66001003

GOLDRING, Luin; LANDOLT, Patricia (2013), "The social production of Non-Citizenship: The consequences of intersecting trajectories of precarious legal status and precarious work". En: Producing and negotiating non-citizenship: Precarious legal status in Canada. University of Toronto Press, pp. 154-173.

GUIZARDI, Menara; MORAGA, Jorge; GARCÉS, Alejandro (2014), "Los procesos migratorios actuales en contextos latinoamericanos: Nuevos itinerarios y reconfiguración de controles fronterizos". Revista de Esudios Sociales v. 48, n. 35, pp. 177-183. Disponible en https://doi.org/10.7440/res48.2014.14

INE DEM. (2020), Estimación de personas extranjeras residentes habituales en Chile al 31 de diciembre 2019. Informe Técnico: Desagregación regional y comunal. Chile. Instituto Nacional de Estadísticas y Departamento de Extranjería y Migración.

KEARNEY, Michael (2004), "The classifying and value-filtering missions of borders". Anthropological Theory, v. 4. n. 2, pp. 131-156 [Consult. 04-07-2021]. Disponible en https://doi.org/10.1177/1463499604042811

KOECHLIN; José; EGUREN, Joaquin (2018), El éxodo venezolano: Entre el exilio y la emigración. Perú, Konrad Adenauer Stiftung, Universidad Antonio Ruiz de Montoya, OIM, OBIMID.

KYMLICKA, Will (2012), Multiculturalism: Success, Failure and the future. Transatlantic Council on Migration. Washington D.C., Migration Policy Institute.

KYMLICKA, Will., \& WAYNE, Norman (1994), Return of the citizen: A survey of recent work on citizenship theory. Ethics, 104(2), 352-381 [Consult. 04-07-2021]. Disponible en https://www.jstor.org/stable/2381582

LESLIE A. (4 julio 2020), Corte le prohíbe a Extranjería exigir a migrantes declaración jurada de que no volverán a Chile. La Tercera [Consult. 20.6.2021]. Disponible https://www.latercera.com/nacional/noticia/corte-le-prohibe-a-extranjeria-exigir-a-migrantesdeclaracion-jurada-de-que-no-volveran-a-chile/L6U5CC2E75F3PNXFI45IX4NXSA/

LIBERONA, Nanette; LÓPEZ, Evelyn (2018), "Crisis del sistema humanitario en Chile. Refugiadas colombianas deslegitimadas en la frontera norte". Estudios Atacameños. Arqueología y Antropología Surandinas, n. 60, pp. 193-212 [Consult. 04-07-2021]. Disponible en http://dx.doi.org/10.4067/S0718-10432018005001502 
ONG, Aihwa (2006), "Mutations in Citizenship" Theory, Culture and Society, v. 23, n. 2-3, pp. 499505 [Consult. 04-07-2021]. Disponible en https://doi.org/10.1177/0263276406064831

RAMOS, Romina; TAPIA, Marcela (2019), "Una mirada heterogénea del espacio fronterizo: El caso de la frontera tarapaqueña (Chile)", Revista CIDOB d'Afers Internacionals, n. 122, pp. 187-210 [Consult. 20.6.2021]. Disponible en https://doi.org/10.24241/rcai.2019.122.2.187

RIVERA, V. (11 de marzo 2021) Chile prepara vuelos para seguir con el plan de expulsión": la campaña del gobierno para frenar ingreso ilegal de inmigrantes. La Tercera.

R4V (2020). RMP2020 Para refugiados y migrantes de Venezuela. Plan de respuesta para refugiados $y$ migrantes [Consult. 20.6.2021]. Disponible en https://r4v.info/es/documents/details/74747

SASSEN, Saskia (2002), "The repositioning of citizenship: Emergent subjects and spaces for politics", Berkeley Journal of Sociology, n. 46, pp. 4-25 [Consult. 04-07-2021]. Disponible en https://www.jstor.org/stable/41035566

Servicio Jesuita a Migrantes (2021), Migración en Chile. Anuario 2020. Medidas migratorias, vulnerabilidad y oportunidades en un año de pandemia. Santiago, Chile, SJM [Consult. 04-072021]. Disponible en https://www.migracionenchile.cl/publicaciones

Sobre los migrantes en el norte de Chile. Por RECHISAM. (2021, marzo 2). Le Monde diplomatique [Consult. 04-07-2021]. Disponible en https://www.lemondediplomatique.cl/sobre-los-migrantesen-el-norte-de-chile-por-rechisam.html

SOYSAL, Yasmin, (1995), Limits of Citizenship. Migrants and Posnational Membership in Europe. Chicago, University of Chicago Press.

STEFONI, Carolina; BLUKACZ, Alice; CABIESES, Báltica; VELEZ, Wualter; SALDIVIA, José Manuel; MUJICA, Ana (2021), Inserción sociolaboral de la población venezolana en Chile. KAS.

STEFONI, Carolina; BRITO, Sebastián (2019), "Migraciones y migrantes en los medios de prensa en Chile: La delicada relación entre las políticas de control y los procesos de racialización". Revista de Historia Social y de las Mentalidades, v. 23, n. 2, pp.1-28 [Consult. 20.6.2021]. Disponible en https://doi.org/10.35588/rhsm.v23i2.4099

EL MOSTRADOR (11 de febrero, 2021), Vacunación: Académicos y organizaciones sociales advierten que "excluir a migrantes con visa de turista es arriesgado y no tiene fundamento".

VÁSQUEZ, Jorge; FINN, Victoria; UMPIERREZ, Sebastián (2021), "Cambiando la cerradura. Intenciones legislativas del proyecto de ley de migraciones en Chile. Colombia Internacional, $\mathrm{n}$. 106, pp. 57-87 [Consult. 20.6.2021]. Disponible en https://doi.org/10.7440/colombiaint106.2021.03

WIEVIORKA, Michel (2002), El racismo Una Introducción. La Paz, Plural Editores.

ZAPATA-BARRERO, Ricard (2013), "Fundamentos de las políticas interculturales en las ciudades: Respuestas a tres preguntas frecuentes". En Manual para el diseño de políticas interculturales (pp. 45-63). Barcelona, Universitat Pompeu Fabra. 


\begin{abstract}
This article analyzes the coexistence and relationship between two approaches that the State has maintained towards the migrant population in Chile during the current COVID-19 pandemic. The first one arises from the universal Human Rights approach that has guided the advances in the access to the health system for the migrant population. The second one, arises from an exclusionary approach developed by the national security perspective, with a strong focus on the control of irregular migration. At a first glance, both approaches may seem opposite, but the truth is that they have been applied simultaneously, although with variations in intensity according to the political context. Based on previous work carried out by the researchers, we will analyze how both approaches have impacted the Venezuelan population in the country. We will focus on the Venezuelan case since today it represents $30 \%$ of the foreign population and because it has been one of the focuses of the measures implemented by the government in the last year.
\end{abstract}

Keywords: Venezuelan migration; pandemic; COVID 19; human rights; health.

\title{
Resumo
}

O presente artigo analisa a coexistência e a relação entre dois enfoques que o Estado manteve em relação à população migrante no Chile durante a atual pandemia de COVID-19. O primeiro está associado à perspectiva universalista dos direitos humanos, a qual tem norteado os avanços no acesso à saúde da população migrante. A segunda, por sua vez, é de caráter excludente e decorre de uma visão securitista com o foco no controle da migração irregular. Em uma primeira leitura, ambos os enfoques podem parecer opostos, mas a verdade é que têm sido aplicados simultaneamente, embora com variações de intensidade de acordo com os diferentes contextos políticos. Com base em trabalhos anteriores realizados pelas pesquisadoras, analisaremos como ambas os enfoques têm impactado a população venezuelana no país. Vamos nos concentrar no caso venezuelano posto que hoje representa $30 \%$ da população estrangeira e porque tem sido um dos focos das medidas implementadas pelo governo no ano passado.

Palavras-chave: Migração venezuelana; pandemia; COVID19; direitos humanos; saúde. 